University of Wollongong

Research Online

Faculty of Informatics - Papers (Archive)

Faculty of Engineering and Information

Sciences

$1-1-2000$

\title{
An examination of the efficiency of Australian crop variety evaluation programmes
}

Brian R. Cullis

University of Wollongong, bcullis@uow.edu.au

A B. Smith

Wagga Wagga Agricultural Institute, alismith@uow.edu.au

C Hunt

Waite Institute, South Australia

Arthur R. Gilmour

University of Wollongong, agilmour@uow.edu.au

Follow this and additional works at: https://ro.uow.edu.au/infopapers

Part of the Physical Sciences and Mathematics Commons

\section{Recommended Citation}

Cullis, Brian R.; Smith, A B.; Hunt, C; and Gilmour, Arthur R.: An examination of the efficiency of Australian crop variety evaluation programmes $2000,213-222$.

https://ro.uow.edu.au/infopapers/2085

Research Online is the open access institutional repository for the University of Wollongong. For further information contact the UOW Library: research-pubs@uow.edu.au 


\title{
An examination of the efficiency of Australian crop variety evaluation programmes
}

\author{
Abstract \\ In this paper we present the analysis of yield data from a broad cross-section of crop variety evaluation \\ programmes (CVEP) conducted in Australia. The main sources of variety by environment interaction are * \\ non-static ' interactions, namely those linked to seasonal influences. These contributed an average of \\ $41.3 \%$ of the total variance. In contrast the static component accounts for only $5.3 \%$ of the total. \\ We develop methods for determining the relative accuracy of CVEP based on selection of newly promoted \\ entries. The accuracy of the current testing regimes for the Australian CVEP under study is determined. \\ The accuracy of alternative schemes, with different numbers of years of testing, numbers of locations per \\ year and numbers of replicates per trial is also examined. Cost effective methods for improving the \\ accuracy of CVEP are discussed. \\ Keywords \\ evaluation, variety, programmes, crop, examination, australian, efficiency \\ Disciplines \\ Physical Sciences and Mathematics \\ Publication Details \\ Cullis, B. R., Smith, A., Hunt, C. \& Gilmour, A. R. (2000). An examination of the efficiency of Australian crop \\ variety evaluation programmes. Journal of Agricultural Science, 135 (3), 213-222.
}




\title{
An examination of the efficiency of Australian crop variety evaluation programmes
}

\author{
B. R. CULLIS ${ }^{1 *}$, A. SMITH ${ }^{1}$, C. HUNT ${ }^{2}$ AND A. GILMOUR ${ }^{3}$ \\ ${ }^{1}$ Wagga Agricultural Institute, Wagga Wagga NSW 2650, Australia \\ ${ }^{2}$ BiometricsSA, Waite Institute, Urrbrae SA 5070, Australia \\ ${ }^{3}$ Orange Agricultural Institute, Orange NSW 2340, Australia
}

(Revised MS received 27 March 2000)

\begin{abstract}
SUMMARY
In this paper we present the analysis of yield data from a broad cross-section of crop variety evaluation programmes (CVEP) conducted in Australia. The main sources of variety by environment interaction are 'non-static' interactions, namely those linked to seasonal influences. These contributed an average of $41.3 \%$ of the total variance. In contrast the static component accounts for only $5 \cdot 3 \%$ of the total.

We develop methods for determining the relative accuracy of CVEP based on selection of newly promoted entries. The accuracy of the current testing regimes for the Australian CVEP under study is determined. The accuracy of alternative schemes, with different numbers of years of testing, numbers of locations per year and numbers of replicates per trial is also examined. Cost effective methods for improving the accuracy of CVEP are discussed.
\end{abstract}

\section{INTRODUCTION}

Resource allocation in crop variety evaluation programmes (CVEP) is an important issue for the plant breeding industry in Australia. There is increasing pressure from governments and funding bodies to reduce the cost of obtaining information regarding the comparative performance of elite lines and commercial varieties. A cost reduction may, however, affect the reliability of the information to an extent that would decrease the response to selection. The economic impact of such outcomes has been examined in detail by Brennan et al. (1998) for the wheat variety evaluation programme conducted by NSW Agriculture. This type of study requires estimates of the relative magnitude of the sources of variation in data arising from CVEP. Brennan et al. (1998) used variance components from Cullis et al. (1996), who examined yield data for 1982-1991 for the NSW wheat programme.

The Australian Crop Accreditation System (ACAS) funded by the Grains Research and Development Corporation stipulates minimal specifications for the release of accredited data on a range of traits for most of the commercially significant crops grown in Australia. In particular, for yield, specific details

* To whom all correspondence should be addressed. Email: brian.cullis@agric.nsw.gov.au concerning the numbers of locations, years and replications are given. The statistical and economic bases for these criteria have not been rigorously developed.

Thus the primary objective of this paper is to enumerate the relative magnitude of sources of variation (variance components) in current Australian CVEP. A secondary aim is to develop a mechanism for evaluating the efficiency of these programmes based on the estimated variance components.

The traditional approach for determining the relative efficiency of CVEP is based on acceptance probabilities (Patterson et al. 1977). These were developed in the context of statistical analyses in which variety effects are considered as fixed. Cullis et al. (1996) assumed random variety effects. The validity of this assumption is discussed in detail by Smith \& Cullis (2000) and supported by Patterson \& Silvey (1980) who imply that the assumption of random variety effects is more appropriate. The aim of our paper is to develop a method for measuring the efficiency of CVEP when variety effects are assumed random. We focus on the two major selection issues in late stage variety testing. The first concerns the retention of entries from one year to the next. Due to the cost of variety evaluation there is a strict limit on the total number of entries tested each year (in most programmes this is about 30). Promising new breeding lines can therefore only be added if existing material 
is discarded. The other key selection issue concerns the commercial release of varieties. When selecting entries to be retained for further testing or to be recommended for commercial release it is important to maintain a large response to selection. We develop methods for the evaluation of CVEP based on response to selection. They require derivation of the posterior distribution of the true and estimated genetic effects.

This paper is arranged in two main sections. In the first section we present estimates of variance components for a range of Australian CVEP. The datasets and statistical methods are described. In the second section we consider the relative efficiency of these CVEP based on the criterion of response to selection. The paper concludes with a discussion of the implication of the accuracy of the current CVEP and ways to improve their efficiency.

\section{DESCRIPTION OF DATA}

Yield data from final stage testing trials (often known as S4 trials) conducted from 1989 to 1997 have been used for this investigation. Table 1 presents the crops and the state-based programmes under consideration. In most cases 6 years of data is used, with a minimum of 4 years. Trials had either 3 (NSW, WA) or 4 replicates (SA, VIC). Trial designs included incomplete block designs (SA and VIC) and neighbour balanced row-column designs (NSW and WA). Individual trial data were analysed using the methods of Gilmour et al. (1997) and variety trial means and weights were saved for subsequent analysis (Smith \& Cullis 2000).

Trial site locations in SA and VIC are almost invariant across years, but this is not the case in NSW and WA. For example, the trial at Ardlethan (NSW) may be moved up to $50 \mathrm{~km}$ from year to year. Trials in SA and VIC have been classified according to year, region and location within region, while trials in NSW and WA are classified by year and region alone. Regions relate either to geographical or rainfall classifications. In NSW, wheat and barley are evaluated in either early (E) or main (M) season trials. Varieties are classified according to maturity and are generally grown in the appropriate trial series. This information is summarized in Table 1.

Varieties were retained in the data-sets if they appeared in at least six trials. Variety covariates were

Table 1. Description of the data-sets used

\begin{tabular}{|c|c|c|c|c|c|}
\hline Crop & Years & Regions & Region type & Locations & Trials \\
\hline \multicolumn{6}{|c|}{ New South Wales (NSW) } \\
\hline Barley (E) & $92-97$ & 6 & Geog & - & 124 \\
\hline Barley (M) & $92-97$ & 6 & Geog & - & 335 \\
\hline Wheat (E) & $90-97$ & 4 & Geog & - & 218 \\
\hline Wheat (M) & $90-97$ & 4 & Geog & - & 402 \\
\hline Lupins & $90-97$ & 2 & Rain & 33 & 113 \\
\hline Peas & $90-97$ & 2 & Geog & - & 86 \\
\hline \multicolumn{6}{|c|}{ South Australia (SA) } \\
\hline Wheat & $92-97$ & 6 & Geog & 26 & 147 \\
\hline Barley & $92-97$ & 6 & Geog & 21 & 115 \\
\hline Oats & $92-97$ & 6 & Geog & 16 & 82 \\
\hline Lentils & $92-97$ & 4 & Geog & 8 & 36 \\
\hline Peas & $92-97$ & 4 & Rain & 13 & 62 \\
\hline Canola & $94-97$ & 6 & Geog & 19 & 54 \\
\hline Lupins & $92-97$ & 5 & Geog & 19 & 81 \\
\hline \multicolumn{6}{|l|}{ Victoria (VIC) } \\
\hline Wheat & $89-97$ & 7 & Geog & 40 & 260 \\
\hline Barley & $92-97$ & 4 & Geog & 25 & 112 \\
\hline Lentils & $92-97$ & 2 & Geog & 14 & 40 \\
\hline Peas & $92-97$ & 5 & Geog & 22 & 79 \\
\hline \multicolumn{6}{|c|}{ Western Australia (WA) } \\
\hline Wheat & $91-97$ & 19 & Geog & - & 495 \\
\hline Barley & $91-97$ & 20 & Geog & - & 338 \\
\hline Oats & $91-97$ & 18 & Geog & - & 456 \\
\hline Lupins & $92-97$ & 21 & Geog & - & 310 \\
\hline Peas & $92-97$ & 21 & Geog & - & 208 \\
\hline
\end{tabular}


Table 2. Description of variety covariates

\begin{tabular}{ll}
\hline \hline Crop & \multicolumn{1}{c}{ Variety Covariate } \\
\hline NSW & \\
Lupins & Type: $1=$ Angustifolius; $2=$ Albus \\
SA & \\
Wheat & Type: $1=$ Durum; $2=$ Other \\
Oats & Type $1=$ Hulless; $2=$ Dwarf; $3=$ Tall \\
Lentils & Maturity: $1=$ Early maturing; $2=$ Mid; \\
& $3=$ Late \\
WA & \\
Oats & Type: $1=$ Dwarf; $2=$ Tall \\
\hline \hline
\end{tabular}

recorded where appropriate (see Table 2). For example, for lupins in NSW, the two species are grown in the same trials, though variety recommendation and release is only relevant within species.

Table 3 presents a range of summary statistics for each data-set. Several of the crops of lesser commercial value have limited coverage of locations and varieties, however the size of the data-sets for wheat and barley for all states is significant. The range of yields for each data-set reflects the fluctuations in growing season rainfall experienced in the Australian cropping belt. There is a high turn-over of varieties. In particular WA and VIC discard over $50 \%$ of varieties after one year of testing.

\section{Statistical models}

The total variation in the data is divided into components based on variety main effects, variety by environment interaction and error arising from the fact that the data are estimated means. Environments are partitioned into regions $(\mathrm{R})$, locations within regions (R.L) and years (Y). The actual subdivision depends on the state and crop programme. The major differences are due to the use of invariant trial sites (SA and VIC) and the inclusion of variety covariates. The main effects of the variety covariates are included as fixed effects; interactions of the covariates with environments are included as random effects. Table 4 presents the ANOVA decomposition which was adopted for the analysis of these data. Terms involving

Table 3. Summary statistics for data-sets

\begin{tabular}{|c|c|c|c|c|c|c|c|}
\hline \multirow[b]{2}{*}{ Crop } & \multirow{2}{*}{$\begin{array}{c}\text { Number of } \\
\text { means }\end{array}$} & \multicolumn{2}{|c|}{ Yield (t/ha) } & \multirow{2}{*}{$\begin{array}{l}\text { Number of } \\
\text { varieties }\end{array}$} & \multicolumn{3}{|c|}{$\%$ varieties tested } \\
\hline & & mean & range & & 1 year & 2 years & $\geqslant 3$ years \\
\hline \multicolumn{8}{|l|}{ NSW } \\
\hline Barley (E) & 1851 & $3 \cdot 36$ & $(1 \cdot 03,7 \cdot 48)$ & 109 & 39 & 30 & 31 \\
\hline Barley (M) & 10211 & $3 \cdot 31$ & $(0 \cdot 42,6 \cdot 55)$ & 400 & 43 & 28 & 29 \\
\hline Wheat (E) & 2985 & $3 \cdot 74$ & $(0 \cdot 37,8 \cdot 70)$ & 70 & 37 & 19 & 44 \\
\hline Wheat (M) & 7289 & $3 \cdot 50$ & $(0 \cdot 32,8 \cdot 13)$ & 151 & 46 & 13 & 41 \\
\hline Lupins & 1889 & 1.69 & $(0 \cdot 18,3 \cdot 99)$ & 124 & 62 & 19 & 19 \\
\hline Peas & 2330 & $2 \cdot 03$ & $(0 \cdot 25,4 \cdot 43)$ & 177 & 22 & 27 & 51 \\
\hline \multicolumn{8}{|l|}{ SA } \\
\hline Wheat & 5389 & $2 \cdot 25$ & $(0 \cdot 24,5 \cdot 83)$ & 97 & 45 & 21 & 34 \\
\hline Barley & 2458 & $2 \cdot 66$ & $(0 \cdot 28,5 \cdot 91)$ & 47 & 28 & 30 & 43 \\
\hline Oats & 2065 & $2 \cdot 80$ & $(0 \cdot 36,6 \cdot 25)$ & 66 & 52 & 20 & 29 \\
\hline Lentils & 325 & 1.62 & $(0 \cdot 31,3 \cdot 39)$ & 14 & 7 & 21 & 71 \\
\hline Peas & 1205 & $2 \cdot 06$ & $(0 \cdot 28,3 \cdot 61)$ & 41 & 34 & 12 & 54 \\
\hline Canola & 1223 & 1.73 & $(0 \cdot 41,3 \cdot 35)$ & 112 & 64 & 23 & 13 \\
\hline Lupins & 950 & 1.64 & $(0 \cdot 16,4 \cdot 19)$ & 34 & 18 & 26 & 56 \\
\hline \multicolumn{8}{|l|}{ VIC } \\
\hline Wheat & 7942 & $3 \cdot 10$ & $(0 \cdot 27,8 \cdot 26)$ & 174 & 57 & 17 & 26 \\
\hline Barley & 3309 & $2 \cdot 96$ & $(0 \cdot 40,6 \cdot 29)$ & 107 & 64 & 21 & 15 \\
\hline Lentils & 401 & $1 \cdot 30$ & $(0 \cdot 09,3 \cdot 27)$ & 33 & 48 & 21 & 30 \\
\hline Peas & 2381 & $2 \cdot 19$ & $(0 \cdot 24,4 \cdot 69)$ & 145 & 41 & 17 & 42 \\
\hline \multicolumn{8}{|l|}{ WA } \\
\hline Wheat & 12955 & $2 \cdot 29$ & $(0 \cdot 31,5 \cdot 69)$ & 197 & 52 & 20 & 28 \\
\hline Barley & 6376 & $2 \cdot 52$ & $(0 \cdot 27,5 \cdot 76)$ & 167 & 69 & 15 & 17 \\
\hline Oats & 6743 & $2 \cdot 49$ & $(0 \cdot 69,5 \cdot 57)$ & 150 & 51 & 25 & 23 \\
\hline Lupins & 4765 & 1.47 & $(0 \cdot 17,2 \cdot 97)$ & 130 & 68 & 15 & 18 \\
\hline Peas & 2915 & 1.42 & $(0 \cdot 21,3 \cdot 37)$ & 98 & 52 & 24 & 23 \\
\hline
\end{tabular}


Table 4. ANOVA decomposition

\begin{tabular}{|c|c|c|}
\hline Term & Decomposition & Type \\
\hline \multicolumn{3}{|c|}{ Variety } \\
\hline & variety & $\mathrm{R}$ \\
\hline \multicolumn{3}{|c|}{ Environment } \\
\hline & year $\dagger$ & $\begin{array}{l}F \\
F\end{array}$ \\
\hline & $\begin{array}{l}\text { region } \dagger \\
\text { region.loc*t }\end{array}$ & $\begin{array}{l}F \\
F\end{array}$ \\
\hline & year.region $\dagger$ & $\mathrm{F}$ \\
\hline & year.region.loc*† & $\mathrm{F}$ \\
\hline \multicolumn{3}{|c|}{ Variety.Environment } \\
\hline & variety.year & $\mathrm{R}$ \\
\hline & variety.region & $\mathrm{R}$ \\
\hline & variety.region.loc* & $\mathrm{R}$ \\
\hline & variety.year.region & $\mathrm{R}$ \\
\hline & variety.environment: & $\mathrm{R}$ \\
\hline \multicolumn{3}{|l|}{ Error } \\
\hline & error & $\mathrm{R}$ \\
\hline
\end{tabular}

* These decompositions were included for SA and VIC data-sets.

$\dagger$ For computational efficiency these effects were not fitted but were replaced by a single factor indexing environments. This produces equivalent estimates of variance components. \$ This term represents the remaining variety by environment interactions.

variety covariates are excluded for brevity. Note that the term 'variety.environment' (V.E) denotes residual variety by environment interaction. It usually reflects the highest order interaction, for example, V.Y.R.L.

All analyses were conducted in ASREML (Gilmour et al. 1999), a programme for estimation of variance components using REML (Patterson \& Thompson 1971). It uses the average information algorithm (Gilmour et al. 1995) and sparse matrix methods. This enables very large data-sets to be analysed. For example the mixed model for the WA wheat data involved 45452 equations. Trial mean yields are weighted to account for error variance heterogeneity between trials, unequal replication and spatial adjustments within trials (see Smith \& Cullis 2000).

\section{VARIANCE COMPONENTS: RESULTS AND DISCUSSION}

REML estimates of the variance components are presented in Table 5 as percentages of total variance. The major source of variation is within-trial error, ranging from $25 \%$ of total variance up to $61 \%$. The next largest source of variation was attributable to the high order variety by environment interactions, V.E. This ranged from $16 \%$ to $60 \%$. Variance components associated with $\mathrm{V}$ and $\mathrm{V}$. R were small by comparison, ranging from $5 \%$ to $33 \%$ for $\mathrm{V}$ and $0 \%$ to $8 \%$ for V.R. The impact of these results is significant for the reporting of results. Variety effects for variety by region summaries are reported as the sum of the Best Linear Unbiased Predictors (BLUPs) of the variety and variety by region effects (Smith \& Cullis 2000). These effects are often very small as a result of the size of the $\mathrm{V}$ and $\mathrm{V}$. R components relative to the total of the other components.

CVEP have traditionally focused on the importance of regionally based variety recommendations. This implies that a significant amount of the variety by environment interaction can be explained by the V.R or the V.R.L terms. The results from this study do not support this argument. To illustrate this more clearly consider the classification of variety by environment components as 'static' (sources which remain constant from year to year, namely V.R+V.R.L) or 'non-static' (sources linked to seasonal variation, V.Y+V.Y.R+V.E). The mean static variety by environment variance is $5 \cdot 3 \%$ compared with $41.3 \%$ for the non-static component.

These results are consistent with the findings of Cullis et al. (1996) and Frensham et al. (1997) who demonstrate that more complex reporting of varietal performance is required. This would include the use of both environmental and varietal covariates to better explain the non-static component. Current work is focused on the derivation of data-dependent environmental covariates which explain large proportions of the variety by environment variance (Piepho 1997; Smith et al. 1998). This is discussed in greater detail in the final discussion of results.

\section{ACCURACY OF CROP VARIETY EVALUATION PROGRAMMES}

In this section we evaluate the relative accuracy of a range of testing schemes (including current practice) for all of the CVEP examined in the section on variance components. The effect of altering the number of years of testing, the number of trials per year and the number of replicates per trial is investigated. Schemes are compared on the basis of the yield response associated with the selection of entries to be retained for further testing or recommended for commercial release.

Varietal selection and recommendation is based on yield estimates from the analysis of data from all relevant CVEP trials. Smith \& Cullis (2000) describe the mixed model analysis currently used in most Australian CVEP. The analysis provides BLUPs of variety and variety by region effects. Broad-based selection decisions are based on the former whereas selections on a regional basis involve the sum of the two.

A key determinant of the accuracy of a CVEP is the correlation between the true variety effects and those predicted from the mixed model analysis. The 
Table 5. REML estimates of variance components as a percentage of total variance for all CVEP; variety by environment components classified as static or non-static

\begin{tabular}{|c|c|c|c|c|c|c|c|c|}
\hline \multirow[b]{2}{*}{ Crop } & \multicolumn{3}{|c|}{ Static } & \multicolumn{3}{|c|}{ Non-static } & \multirow[b]{2}{*}{ Error } & \multirow{2}{*}{$\begin{array}{c}\text { Total } \\
\text { (t/ha) }\end{array}$} \\
\hline & $\mathrm{V}$ & V.R & V.R.L & V.Y & V.Y.R & V.E & & \\
\hline \multicolumn{9}{|l|}{ NSW } \\
\hline Barley (E) & 15 & 0 & - & 12 & 12 & 36 & 25 & 0.571 \\
\hline Barley (M) & 19 & 3 & - & 5 & 4 & 34 & 36 & $0 \cdot 443$ \\
\hline Wheat (E) & 12 & 3 & - & 9 & 5 & 37 & 34 & $0 \cdot 416$ \\
\hline Wheat (M) & 12 & 1 & - & 6 & 4 & 38 & 39 & $0 \cdot 343$ \\
\hline Lupins & 5 & 0 & 4 & 5 & 0 & 25 & 60 & 0.094 \\
\hline Peas & 15 & 2 & - & 14 & 5 & 28 & 35 & $0 \cdot 344$ \\
\hline \multicolumn{9}{|l|}{ SA } \\
\hline Wheat & 15 & 6 & 3 & 9 & 9 & 23 & 35 & $0 \cdot 155$ \\
\hline Barley & 13 & 3 & 4 & 15 & 4 & 30 & 31 & $0 \cdot 243$ \\
\hline Oats & 13 & 1 & 6 & 5 & 2 & 30 & 44 & 0.335 \\
\hline Lentils & 5 & 0 & 5 & 5 & 5 & 26 & 54 & $0 \cdot 206$ \\
\hline Peas & 9 & 4 & 4 & 6 & 1 & 34 & 42 & $0 \cdot 246$ \\
\hline Canola & 33 & 0 & 5 & 1 & 4 & 11 & 45 & $0 \cdot 176$ \\
\hline Lupins & 5 & 2 & 4 & 8 & 3 & 17 & 61 & $0 \cdot 145$ \\
\hline \multicolumn{9}{|l|}{ VIC } \\
\hline Wheat & 8 & 7 & 2 & 10 & 4 & 25 & 43 & $0 \cdot 240$ \\
\hline Barley & 14 & 2 & 5 & 13 & 3 & 26 & 37 & 0.318 \\
\hline Lentils & 22 & 0 & 0 & 36 & 0 & 15 & 27 & 0.338 \\
\hline Peas & 17 & 0 & 6 & 8 & 5 & 20 & 45 & $0 \cdot 340$ \\
\hline \multicolumn{9}{|l|}{ WA } \\
\hline Wheat & 18 & 8 & - & 5 & 8 & 27 & 34 & $0 \cdot 135$ \\
\hline Barley & 19 & 7 & - & 5 & 3 & 35 & 31 & $0 \cdot 193$ \\
\hline Oats & 16 & 6 & - & 5 & 4 & 39 & 31 & $0 \cdot 189$ \\
\hline Lupins & 11 & 8 & - & 3 & 6 & 29 & 42 & 0.080 \\
\hline Peas & 7 & 5 & - & 4 & 8 & 34 & 43 & $0 \cdot 108$ \\
\hline
\end{tabular}

stronger is the correlation the higher is the response to selection. In order to calculate the correlation we must derive the joint distribution of the true and predicted effects. In the following we present results regarding the joint distribution of true and predicted genetic effects in a balanced multi-environment trial (MET) data-set. Results for a general linear mixed model are given in the appendix. For simplicity, proofs are omitted but can be found in Hunt \& Cullis (1999).

\section{Theoretical results}

Consider a balanced MET data-set in which $n_{1}$ varieties have been tested for $n_{2}$ years. Each year a total of $n_{3} n_{4}$ trials are conducted, where $n_{3}$ is the number of regions and $n_{4}$ the number of fixed locations within regions. Each trial has $n_{5}$ replicates. This setting reflects the CVEP in SA and VIC.

The corresponding linear mixed model for the data vector, $y$, is

$$
\begin{aligned}
y= & X \tau+Z_{1} u_{1}+Z_{12} u_{12}+Z_{13} u_{13}+Z_{123} u_{123}+Z_{134} u_{134} \\
& +Z_{1234} u_{1234}+e
\end{aligned}
$$

where $X$ is the design matrix for the fixed effects of environment, a factor representing the factorial combination of year $(\mathrm{Y})$, region $(\mathrm{R})$ and location $(\mathrm{L})$. The random effects design matrices, $Z_{(i)}$, are the design matrices for variety (V), V.Y, V.R, V.Y.R, V.R.L and V.Y.R.L. The vectors $\tau$ and $u_{(i)}$ are the corresponding fixed and random effects and $e$ is the vector of errors ( or $u_{12345}$ ). The mixed model analysis provides Best Linear Unbiased Estimates (BLUEs) of the fixed effects, denoted $\hat{\tau}$, and BLUPs of the random effects, denoted $\tilde{u}_{(i)}$ (see appendix). The decomposition of the total variance is presented in ANOVA form in Table 6 . The associated degrees of freedom involve $v_{i}$ $=n_{i}-1$.

Each pair of vectors of random effects in equation 1 is assumed to be independent. Further we assume that the elements of each vector are identically and independently distributed Gaussian deviates with mean zero and variance $\sigma_{(i)}^{2}$, viz $\left(\sigma_{1}^{2}, \sigma_{12}^{2}, \sigma_{13}^{2}, \sigma_{123}^{2}\right.$, $\left.\sigma_{134}^{2}, \sigma_{1234}^{2}, \sigma_{12345}^{2}=\sigma^{2}\right)$. Table 6 presents the stratum variances, $\theta_{i}$ (see Nelder 1964; Hunt \& Cullis 1999).

Simplified expressions for the variance matrix of the true and predicted variety effects as functions of 
Table 6. ANOVA decomposition for random terms in the balanced MET

\begin{tabular}{|c|c|c|c|}
\hline Strata & D.F. & & Stratum variance $\left(\sigma^{2}=\sigma_{12345}^{2}\right)$ \\
\hline \multicolumn{4}{|l|}{ Variety } \\
\hline variety $(\mathrm{V})$ & $v_{1}$ & $\theta_{1}$ & $n_{2} n_{3} n_{4} n_{5} \sigma_{1}^{2}+n_{3} n_{4} n_{5} \sigma_{12}^{2}+n_{2} n_{4} n_{5} \sigma_{13}^{2}+n_{4} n_{5} \sigma_{123}^{2}+n_{2} n_{5} \sigma_{134}^{2}+n_{5} \sigma_{1234}^{2}+\sigma^{2}$ \\
\hline \multicolumn{4}{|r|}{ 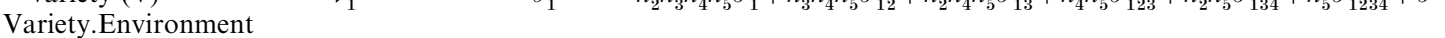 } \\
\hline V.year (V.Y) & $n_{1} v_{2}$ & $\theta_{2}$ & $n_{3} n_{4} n_{5} \sigma_{12}^{2}+n_{4} n_{5} \sigma_{123}^{2}+n_{5} \sigma_{1234}^{2}+\sigma^{2}$ \\
\hline V.region (V.R) & $n_{1} v_{3}$ & $\theta_{3}^{2}$ & $n_{2} n_{4} n_{5} \sigma_{13}^{2}+n_{4} n_{5} \sigma_{123}^{2}+n_{2} n_{5} \sigma_{134}^{2}+n_{5} \sigma_{1234}^{2}+\sigma^{2}$ \\
\hline V.Y.R & $n_{1} v_{2} v_{3}$ & $\theta_{4}$ & $n_{4} n_{5} \sigma_{123}^{2}+n_{5} \sigma_{1234}^{2}+\sigma^{2}$ \\
\hline V.R.loc (V.R.L) & $n_{1} n_{3} v_{4}$ & $\theta_{5}$ & $n_{2} n_{5} \sigma_{134}^{2}+n_{5} \sigma_{1234}^{2}+\sigma^{2}$ \\
\hline V.Y.R.L & $n_{1} n_{3} v_{2} v_{4}$ & $\theta_{6}$ & $n_{5} \sigma_{1234}^{2}+\sigma^{2}$ \\
\hline \multicolumn{4}{|l|}{ Error } \\
\hline V.Y.R.L.rep & $n_{1} n_{2} n_{3} n_{4} \nu_{5}$ & $\theta_{7}$ & $\sigma^{2}$ \\
\hline
\end{tabular}

Table 7. Number of trials within region per year

\begin{tabular}{lllr}
\hline \hline Crop & Min & Max & Mean \\
\hline NSW & & & \\
Barley (E) & 1 & 12 & 4 \\
Barley (M) & 3 & 21 & 10 \\
Wheat (E) & 1 & 17 & 7 \\
Wheat (M) & 4 & 29 & 13 \\
Lupins & 1 & 20 & 7 \\
Peas & 5 & 10 & 7
\end{tabular}

SA

Wheat

Barley

Oats

Lentils

Peas

Canola

Lupins

VIC

Wheat

Barley

Lentils

Peas

WA

\begin{tabular}{llrl} 
Wheat & 1 & 14 & 4 \\
Barley & 1 & 6 & 3 \\
Oats & 1 & 11 & 4 \\
Lupins & 1 & 7 & 3 \\
Peas & 1 & 6 & 2 \\
\hline
\end{tabular}

the stratum variances can be obtained. These are presented in the following two theorems (Hunt \& Cullis 1999).

Theorem 1 The variance matrix of $\left(u_{1}, \tilde{u}_{1}\right)$ for the balanced MET above is

$$
\left[\begin{array}{cc}
\sigma_{1}^{2} I_{n_{1}} & \sigma_{1}^{2} h_{1}^{2} K_{1} \\
\operatorname{symm} & \sigma_{1}^{2} h_{1}^{2} K_{1}
\end{array}\right]
$$

where $K_{1}=I_{n_{1}}-J_{n_{1}} / n_{1}, h_{1}^{2}=\sigma_{1}^{2} n_{2} n_{3} n_{4} n_{5} / \theta_{1}$ and $J_{n_{1}}$ is an $n_{1} \times n_{1}$ matrix of ones.

Theorem 2 The vector of true and predicted variety effects within a region for the balanced MET above is given by $\left(u_{1}+A_{13} u_{13}, \tilde{u}_{1}+A_{13} \tilde{u}_{13}\right)$, for a suitably chosen matrix $A_{13}$. The associated variance matrix is

$$
\left[\begin{array}{cc}
\left(\sigma_{1}^{2}+\sigma_{13}^{2}\right) I_{n_{1}} & b_{13}^{2} K_{1} \\
\operatorname{symm} & b_{13}^{2} K_{1}
\end{array}\right]
$$

where

$$
\begin{aligned}
b_{13}^{2} & =\sigma_{1}^{2} h_{1}^{2}+\sigma_{13}^{2} h_{13}^{2}+\frac{\sigma_{13}^{2} h_{1}^{2}}{n_{3}}\left(\frac{\sigma_{13}^{2}}{n_{3} \sigma_{1}^{2}}+2-\frac{h_{13}^{2}}{h_{1}^{2}}\right) \\
h_{13}^{2} & =\sigma_{13}^{2} n_{2} n_{4} n_{5} / \theta_{3}
\end{aligned}
$$

\section{Response to selection for balanced METs}

The yield response associated with selection of entries to be retained for further testing or recommended for commercial release is presented in Table 8 . We have assumed that 30 entries have been tested in a balanced MET and that the 5 entries with the highest BLUPs have been selected. The number of regions is as given in Table 1 for each crop. The number of locations per region was set to the mean number for each crop (see Table 7). The number of replicates was set to 3 in all cases. Varying the number of replicates from 2 to 4 had little effect on the responses. Responses are presented for both overall and regional selection and for 1, 2 and 3 years of testing. They are expressed relative to the maximum achievable response for the given configuration, that is, when the heritability is unity. By definition, this relative response to selection is equivalent to the correlation between the observed and predicted variety effects.

The responses in Table 8 for 1 and 2 years of testing correspond to the current testing regimes. Alternative schemes involving larger numbers of years and locations per region were investigated. The response to selection for a range of numbers of years and 
Table 8. Response to selection (proportion of maximum) for each CVEP for one, two and three years of testing, three replicates and the current number of regions and locations per region

\begin{tabular}{|c|c|c|c|c|c|c|c|c|}
\hline \multirow[b]{2}{*}{ Crop } & \multicolumn{4}{|c|}{ Overall } & \multicolumn{4}{|c|}{ Regional } \\
\hline & 1 year & 2 years & 3 years & $\max (\mathrm{t} / \mathrm{ha})$ & 1 year & 2 years & 3 years & $\max (\mathrm{t} / \mathrm{ha})$ \\
\hline \multicolumn{9}{|l|}{ NSW } \\
\hline Barley (E) & $0 \cdot 72$ & $0 \cdot 82$ & $0 \cdot 86$ & $0 \cdot 300$ & $0 \cdot 72$ & $0 \cdot 82$ & $0 \cdot 86$ & $0 \cdot 300$ \\
\hline Barley (M) & $0 \cdot 86$ & $0 \cdot 92$ & $0 \cdot 94$ & $0 \cdot 293$ & $0 \cdot 85$ & $0 \cdot 91$ & $0 \cdot 91$ & $0 \cdot 314$ \\
\hline Wheat (E) & $0 \cdot 71$ & $0 \cdot 81$ & $0 \cdot 85$ & $0 \cdot 227$ & 0.69 & $0 \cdot 80$ & $0 \cdot 85$ & $0 \cdot 251$ \\
\hline Wheat (M) & $0 \cdot 79$ & $0 \cdot 88$ & $0 \cdot 90$ & $0 \cdot 208$ & $0 \cdot 78$ & $0 \cdot 86$ & $0 \cdot 90$ & $0 \cdot 214$ \\
\hline Lupins & $0 \cdot 57$ & $0 \cdot 70$ & $0 \cdot 77$ & $0 \cdot 070$ & 0.57 & $0 \cdot 70$ & $0 \cdot 77$ & $0 \cdot 070$ \\
\hline Peas & $0 \cdot 67$ & $0 \cdot 77$ & $0 \cdot 81$ & $0 \cdot 231$ & $0 \cdot 67$ & $0 \cdot 78$ & $0 \cdot 83$ & $0 \cdot 248$ \\
\hline \multicolumn{9}{|l|}{ SA } \\
\hline Wheat & $0 \cdot 73$ & $0 \cdot 82$ & $0 \cdot 86$ & $0 \cdot 154$ & 0.71 & $0 \cdot 80$ & $0 \cdot 85$ & $0 \cdot 181$ \\
\hline Barley & $0 \cdot 64$ & $0 \cdot 76$ & $0 \cdot 81$ & $0 \cdot 180$ & $0 \cdot 61$ & $0 \cdot 72$ & $0 \cdot 79$ & $0 \cdot 202$ \\
\hline Oats & $0 \cdot 75$ & $0 \cdot 84$ & $0 \cdot 89$ & $0 \cdot 212$ & 0.73 & $0 \cdot 82$ & $0 \cdot 87$ & $0 \cdot 221$ \\
\hline Lentils & $0 \cdot 52$ & $0 \cdot 64$ & $0 \cdot 70$ & 0.099 & 0.52 & $0 \cdot 64$ & $0 \cdot 70$ & $0 \cdot 099$ \\
\hline Peas & $0 \cdot 66$ & $0 \cdot 76$ & $0 \cdot 81$ & $0 \cdot 154$ & $0 \cdot 62$ & $0 \cdot 74$ & $0 \cdot 80$ & $0 \cdot 185$ \\
\hline Canola & $0 \cdot 95$ & 0.98 & 0.98 & $0 \cdot 247$ & 0.95 & 0.97 & 0.97 & $0 \cdot 248$ \\
\hline Lupins & $0 \cdot 53$ & $0 \cdot 65$ & $0 \cdot 72$ & $0 \cdot 083$ & $0 \cdot 50$ & $0 \cdot 62$ & $0 \cdot 70$ & $0 \cdot 103$ \\
\hline \multicolumn{9}{|l|}{ VIC } \\
\hline Wheat & $0 \cdot 63$ & $0 \cdot 74$ & $0 \cdot 79$ & $0 \cdot 145$ & 0.66 & $0 \cdot 77$ & $0 \cdot 81$ & $0 \cdot 199$ \\
\hline Barley & $0 \cdot 67$ & $0 \cdot 78$ & $0 \cdot 84$ & $0 \cdot 218$ & 0.66 & $0 \cdot 77$ & $0 \cdot 83$ & $0 \cdot 234$ \\
\hline Lentils & $0 \cdot 60$ & $0 \cdot 73$ & $0 \cdot 79$ & $0 \cdot 278$ & $0 \cdot 60$ & $0 \cdot 73$ & 0.79 & $0 \cdot 278$ \\
\hline Peas & $0 \cdot 77$ & $0 \cdot 86$ & $0 \cdot 90$ & $0 \cdot 244$ & 0.77 & $0 \cdot 86$ & $0 \cdot 90$ & $0 \cdot 244$ \\
\hline \multicolumn{9}{|l|}{ WA } \\
\hline Wheat & $0 \cdot 86$ & $0 \cdot 92$ & $0 \cdot 94$ & $0 \cdot 159$ & $0 \cdot 81$ & $0 \cdot 87$ & $0 \cdot 90$ & $0 \cdot 193$ \\
\hline Barley & $0 \cdot 87$ & $0 \cdot 92$ & $0 \cdot 94$ & $0 \cdot 194$ & $0 \cdot 80$ & $0 \cdot 87$ & $0 \cdot 89$ & $0 \cdot 229$ \\
\hline Oats & $0 \cdot 85$ & $0 \cdot 91$ & 0.94 & $0 \cdot 176$ & 0.79 & $0 \cdot 86$ & 0.89 & $0 \cdot 206$ \\
\hline Lupins & $0 \cdot 86$ & $0 \cdot 91$ & $0 \cdot 93$ & $0 \cdot 098$ & $0 \cdot 76$ & $0 \cdot 84$ & $0 \cdot 87$ & $0 \cdot 128$ \\
\hline Peas & $0 \cdot 75$ & $0 \cdot 84$ & $0 \cdot 87$ & $0 \cdot 088$ & $0 \cdot 63$ & $0 \cdot 72$ & $0 \cdot 77$ & $0 \cdot 114$ \\
\hline
\end{tabular}

locations per regions for the wheat and barley CVEP are displayed in Figs 1 and 2. Response to selection for all other CVEP are available on request.

When there is no measurable variety by region interaction, selection is simply based on the overall performance. However, when there is variety by region interaction, selection may either be based on overall or regional performance. This decision rests with the crop variety evaluators and breeders. We present response to selection for both scenarios. When the variety by region interaction variance component is zero, the two sets are identical.

The responses to selection based on a single year of data are poor (Table 8 ). There are substantial gains in using data from 2 years of testing, but the response is still unacceptably low for many crops (only 6 out of the 22 have a response which is at least $90 \%$ of the maximum attainable for overall recommendations).

\section{Discussion of results}

It is relatively easy to obtain 2 years of data for promotion decisions, since most entries have had a single year of testing in S3 trials prior to testing in S4 trials. S3 trials generally involve a much larger number of varieties and are usually conducted at a subset of the S4 locations within each region. It is difficult to extend the length of testing at the S4 stage beyond a single year before making promotion decisions so that alternative methods for increasing response to selection must be sought. Increasing the number of locations per region does not provide the answer. Figs 1 and 2 show that the effect of increasing the number of locations is much less than that of increasing the number of years. In fact, for barley, there is very little effect at all. Additionally there is a significant cost associated with increasing the number of locations per region. There has been a reduction in the scale of testing for most CVEP in Australia over the past 5 to 10 years, and this trend is unlikely to change with current funding.

We believe that the greatest and most cost effective gains can be obtained through the use of a composite $\mathrm{S} 3$ and S4 trial data-set and a more rigorous and appropriate statistical analysis. Conducting an analysis based on combined S3 and S4 data can introduce 


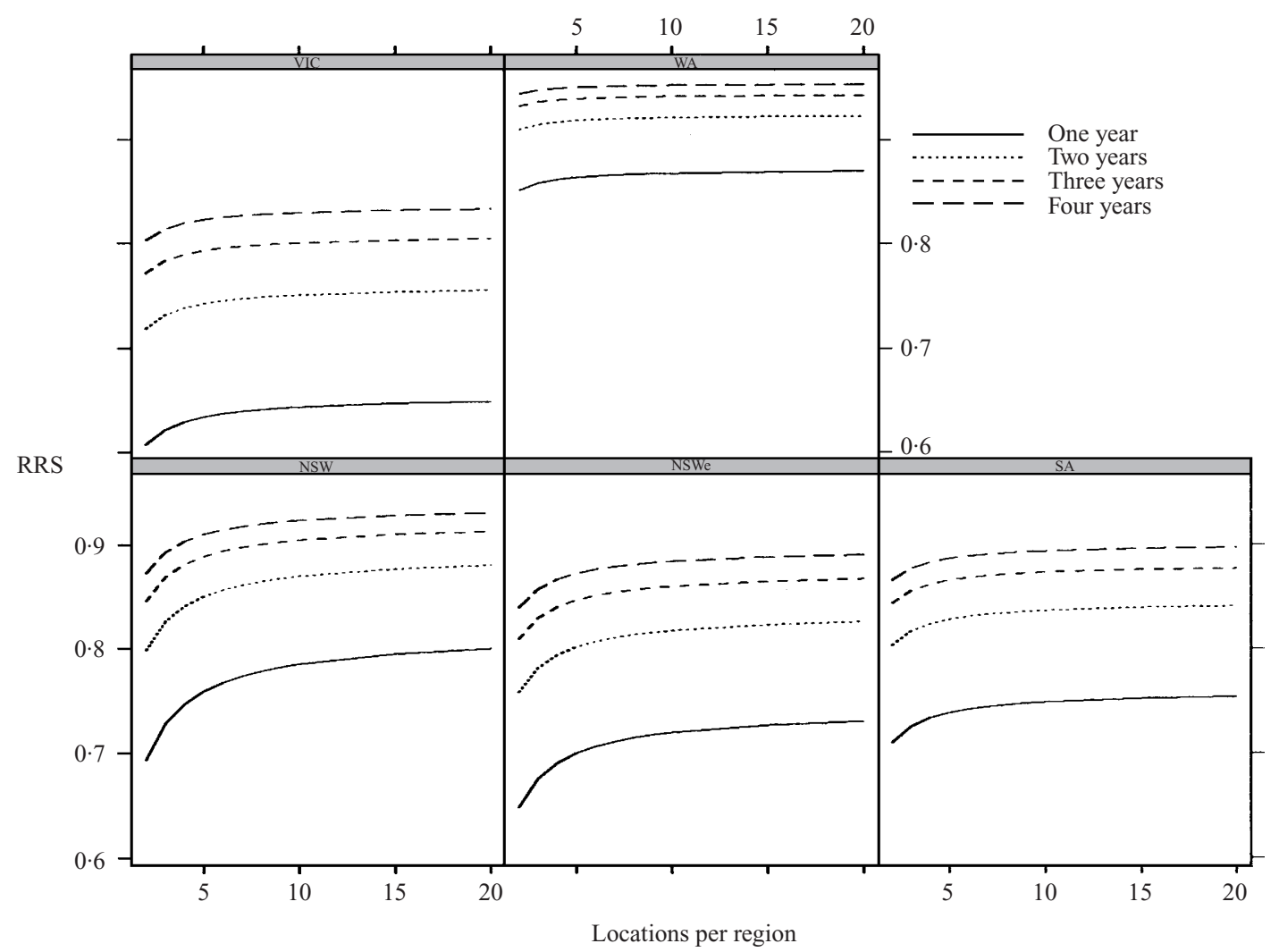

Fig. 1. The effect of the number of years and locations on the relative response to selection (RRS) for wheat CVEP (three replicates and the current number of regions).

bias in the estimation of variance components as there has been selection at the S3 stage (Thompson 1977). This can be avoided by appropriately modelling the genetic variance and covariance structure both between and within S3 and S4 trials. Smith et al. (1998) present an analysis for MET data in which the genetic effects are described by a multiplicative model and the plot errors by a separable spatial model for each trial. They also included important varietal covariates, such as maturity scores to assist with the interpretation of variety by environment interactions. The gains over the more traditional 2-stage variance component approach are numerous.

The multiplicative model approach advocated by Smith et al. (1998) is being used for the analysis of early generation variety trials (Cullis et al. 1998) throughout most public plant breeding programmes in Australia. Data from these METs include only a few environments, but a much larger number of entries than in CVEP trials. There are two main impediments to the adoption of the Smith et al. (1998) approach for the analysis of late stage variety trial data from CVEP. The analysis requires access to original plot data. These data are largely unavailable in electronic form for many CVEP in Australia and therefore the implementation of well designed and efficient database systems for the storage, interrogation and retrieval of CVEP data is a priority. Secondly, the computational burden for large numbers of environments with the current numerical algorithm implemented in ASREML (Gilmour et al. 1999) is prohibitive. This problem is being addressed and we are confident of being able to analyse data-sets with over 100 trials in a one-stage analysis in the near future.

We thank Fiona Thomson, Patrick Lim, Ben Braysher and Dean Diepeveen for their assistance with data collation and analysis. We thank all plant breeders and crop evaluation staff associated with the CVEP under study for their cooperation and the use of their data. In particular, we thank Peter Martin for discussions and support. Ari Verbyla is thanked for comments on an earlier draft of the manuscript. We thank a referee for valuable comments. We gratefully acknowledge the financial support of the Grains Research and Development Corporation. 


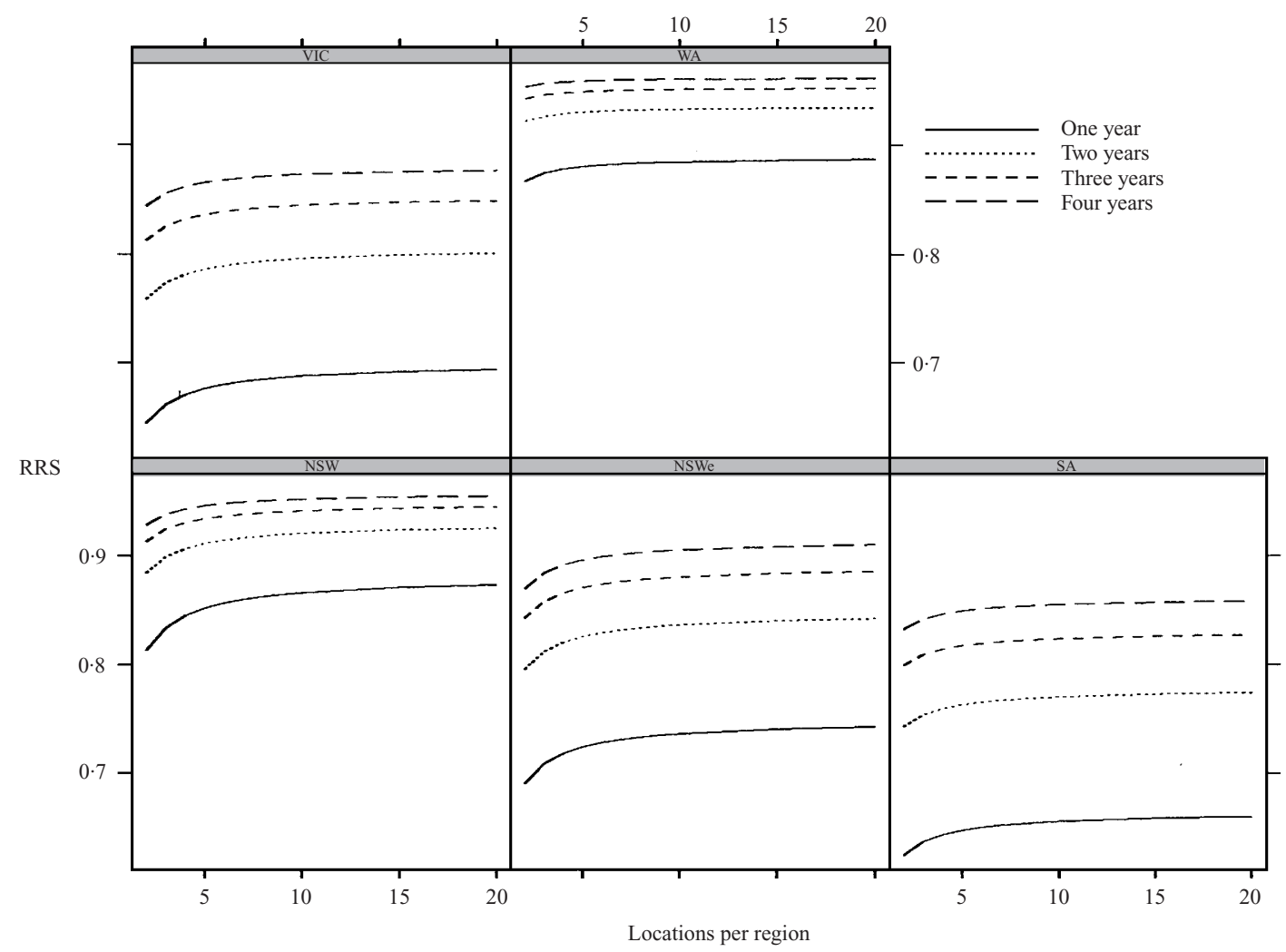

Fig. 2. The effect of the number of years and locations on the relative response to selection (RRS) for barley CVEP (three replicates and the current number of regions).

\section{APPENDIX}

Here we derive the joint distribution of true and predicted random effects in a general linear mixed model. Consider the linear mixed model for the data vector, $y$

$$
y=X \tau+Z u+e
$$

where $e$ is the vector of errors, $\tau^{(t \times 1)}$ is the vector of fixed effects with design matrix $X^{(n \times t)}$ (assumed to have full column rank), $u^{(b \times 1)}$ is the vector of random effects with design matrix $Z^{(n \times b)}$.

We assume that the joint distribution of the random components in equation 2, $(u, e)$ is Gaussian, with mean zero and variance matrix

$$
\left[\begin{array}{ll}
G & 0 \\
0 & R
\end{array}\right]
$$

The marginal distribution of $y$ is then

$$
y \sim \mathrm{N}\left(X \tau,\left(Z G Z^{\prime}+R\right)\right)
$$

The BLUE of $\tau$ and BLUP of $u$ are obtained by solving the mixed model equations, given by
$\left[\begin{array}{cc}X^{\prime} R^{-1} X & X^{\prime} R^{-1} Z \\ Z^{\prime} R^{-1} X & \left(Z^{\prime} R^{-1} Z+G^{-1}\right)\end{array}\right]\left[\begin{array}{c}\hat{\tau} \\ \tilde{u}\end{array}\right]=\left[\begin{array}{c}X^{\prime} R^{-1} y \\ Z^{\prime} R^{-1} y\end{array}\right]$

The matrix on the left hand side of equation 3 is known as the coefficient matrix and is denoted by $C$. Various forms are available for the solutions. For example,

$$
\begin{aligned}
& \hat{\tau}=\left(X^{\prime} V^{-1} X\right)^{-1} X^{\prime} V^{-1} y \\
& \tilde{u}=G Z^{\prime} P y
\end{aligned}
$$

where $V=Z G Z^{\prime}+R$ and

$P=R^{-1}-R^{-1} W C^{-1} W^{\prime} R^{-1}, W=\left[\begin{array}{ll}X & Z\end{array}\right]$.

Theorem 3 The joint distribution of $(u, \tilde{u})$ is Gaussian, with mean zero and variance matrix

$$
\left[\begin{array}{cc}
G & G Z^{\prime} P Z G \\
\text { symm } & G Z^{\prime} P Z G
\end{array}\right]
$$

where $G Z^{\prime} P Z G=G-C^{22}$ and $C^{22}$ is the portion of $C^{-1}$ corresponding to $u$. 


\section{REFERENCES}

Brennan, J. P., Kingwell, R. S., Thomson, F. M. \& Cullis, B. R. (1998). Optimal strategies for regional cultivar testing. Australian Journal of Agricultural and Resource Economics 42, 209-227.

Cullis, B. R., Gogel, B. J., Verbyla, A. P. \& Thompson, R. (1998). Spatial analysis of multi-environment early generation trials. Biometrics 54, 1-18.

Cullis, B. R., Thomson, F. M., Fisher, J. A., Gilmour, A. R. \& Thompson, R. (1996). The analysis of the NSW wheat variety database. I. Modelling trial error variance. Theoretical and Applied Genetics 92, 21-27.

Frensham, A. B., Barr, A. R., Cullis, B. R. \& Pelham, S. D. (1997). The analysis of 10 years of South Australian oat evaluation data. Euphytica 99, 43-56.

Gilmour, A. R., Cullis, B. R. \& Verbyla, A. P. (1997) Accounting for natural and extraneous variation in the analysis of field experiments. Journal of Agricultural, Biological, and Environmental Statistics 2, 269-273.

Gilmour, A. R., Cullis, B. R., Welham, S. J. \& Thompson, R. (1999). ASREML reference manual. Biometric bulletin, No 3. Orange, NSW: NSW Agriculture.

Gilmour, A. R., Thompson, R. \& Cullis, B. R. (1995). AI, an efficient algorithm for REML estimation in linear mixed models. Biometrics 51, 1440-1450.

Hunt, C. \& Cullis, B. R. (1999). The analysis of balanced genotype by environment data. Research Report Series 99/1. The University of Adelaide, South Australia: BiometricsSA.
Nelder, J. A. (1964). The analysis of randomized experiments with orthogonal block structure. I. Block structure and the null analysis of variance. Proceedings of the Royal Society $A$ 283, 147-162.

Patterson, H. D. \& Silvey, V. (1980). Statutory and recommended list trials of crop varieties in the United Kingdom. Journal of Royal Statistical Society A 143, 219-252.

Patterson, H. D., Silvey, V., Talbot, M. \& Weatherup, S. T. C. (1977). Variability of yields of cereal varieties in UK trials. Journal of Agricultural Science, Cambridge $\mathbf{8 9}$, 238-245.

Patterson, H. D. \& Thompson, R. (1971). Recovery of interblock information when block sizes are unequal. Biometrika 31, 100-109.

PIEPHO, H.-P. (1997). Analyzing genotype-environment data by mixed models with multiplicative terms. Biometrics $\mathbf{5 3}$, 761-767.

Smith, A. B. \& Cullis, B. R. (2000). The analysis of crop variety evaluation data in Australia. Australian and New Zealand Journal of Statistics 42, in press.

Smith, A. B., Cullis, B. R., Gilmour, A. \& Thompson, R. (1998). Multiplicative models for interaction in spatial mixed model analyses of multi-environment trial data. In Proceedings of the International Biometrics Conference pp. 91-101.

Thompson, R. (1977). The estimation of heritability with unbalanced data. I. Observations available on parents and offspring. Biometrics 33, 485-495. 